\title{
The Role of Ultrasound Guided IVC-CI versus Central Venous Pressure in Assessment of Critically Ill Patients
}

\author{
RASHEDA AZZAM, M.D. \\ The Department of Anaesthesia and Intensive Care, Faculty of Medicine for Girls, Al-Azhar University
}

\begin{abstract}
Background: Both hypovolemia and volume over load increase the morbidity and mortality of patients. So evaluation of intravascular volume status is the first important step in patients with signs of shock. Use of non invasive method as Inferior Vena Cava (IVC) measurements is one of methods to avoid complications of invasive procedure as central venous pressure monitoring.
\end{abstract}

Aim of Study: This study aimed to provide a useful guide for noninvasive intravascular volume status (as diagnosed and manage) and to evaluating the correlation between Inferior Vena Cava-Collapsibility Index (IVC-CI) measured with ultrasonography versus central venous pressure.

Patients and Methods: This study was a prospective observation study that was conducted on forty critically ill patients of both sexes, aging >!21 years old of ASA (III \& IV) with signs of shock, admitted in the ICU at Al-Zahraa University Hospitals during the last two year (October 2018 till October 2020), were enrolled in the non probability consecutive sampling after approval of the Al-Azhar University Ethical Committee and written informed consent from the patient or the 1 st degree relatives in case of comatosed patient. After were screened for signs of shock, hemodynamic parameters were monitored continuously then $500 \mathrm{ml}$ of Nacl $0.9 \%$ was administered in 15 minutes and clinical response was observed with measures taken by using ultrasound. Then the patients were divided into responder and non responder.

Results: In our study there was 24 patients of 40 patients $(60 \%)$ responded to volume resuscitation. While 16 patients of 40 patients $(40 \%)$ did not respond to volume resuscitation regimen and then blood pressure improved only after introduction of vasopressor as regarding to demographic data, there was no significant difference between two groups, as regarding to heart rate, MAP, and central venous pressure was no significant difference between two groups. In responder group there was strongly correlated that was highly significant of CVP and IVC-CI, in non responder group, there was no correlation between CVP and IVP-CI throughout the study.

Conclusion: Inferior vena cava collapsibility index assessment is relatively safe option and sensitive at least when compared to measuring CVP.

Correspondence to: Dr. Rasheda Azzam, The Department of Anaesthesia and Intensive Care, Faculty of Medicine for Girls, Al-Azhar University
Key Words: Central venous pressure - Inferior vena cavacollapsibility index $(I V C-C I)$.

\section{Introduction}

CRITICALLY patients are prone to develop life threatening complications that require emergency care and Intensive Care Unit (ICU) admission. They can present with specific decompensations. Several critically events that are observed in the general population such as severe sepsis or septic shock. Clinical management of all these entitis requires a specific approach in critically ill patients

Some patients have a hyerdynamic circulation with high cardiac output and low systemic vascular resistance in the absence of infection. Circulatory dysfunction increases the susceptibility of criticallyill patients to develop multiple organ failure and attenuates vascular reaction to vasopressor drugs. Moreover, hypotensive patients require a carefully balanced replacement of volume status, over transfusion is risk for pulmonary edema and congestion and under transfusion causes tissue hypoperfusion which increases the risk of multiple organ failure

Therefore, it is essential to provide adequate fluid resuscitation without "overloading" in order to improve the outcome of the critically ill patients. This requires a careful assessment of the intravascular volume status and fluid responsiveness prior to the institution of fluid therapy. A variety of static and dynamic parameters have been used to assess fluid responsiveness [3].

Central Venous Pressure (CVP) for assessing the fluid status, though not accurate always, is one of the most commonly followed techniques at most hospitals. It's an invasive procedure, time consum- 
ing, has its own risks and complications and requires skilled personnel [4].

Bedside Ultrasound (BUS) is being increasingly used by the intensivists to assess the intravascular volume status and fluid responsiveness by measuring Inferior Vena Cava (IVC) diameter and variation in IVC diameter in relation to respiration [3].It has been studied in several researches since 1979 and is associated with the acceptable results

\section{Aim of the work:}

The aim of this study is to evaluate the relationship between Inferior Vena Cava (IVC) diameter variation ratio measured by Ultrasongraphy (USG) versus Central Venous Pressure (CVP) as measured via central venous catheter, and whether it is reliable for use in diagnosis and management intravascular volume status of patients.

\section{Methods}

This study was a prospective observation study that was conducted on 40 critically ill patients with acute circulatory failure as described later of either sex, aging > 20 years old, admitted in the ICU at Alzahraa University Hospitals during the last two years (October 2018 till October 2020), this study was approved by our Local Ethics Committee in Al-Zahraa University Hospital after obtaining consent from patients or the $1^{\text {st }}$ degree relatives in case of comatosed patient.

Patients with the following criteria were excluded from the study: Patients who needed mechanical ventilation. Deeply comatose patients (Glasgow coma scale < 8/15) which need mechanical ventilation. INR-coagulation disorder (Platelet count INR >2.5 platelet <20). Patients in whom we could not visualize the inferior vena cava due to the large body index BMI $>40 \mathrm{Kg} / \mathrm{m}^{2}$ or excessive intra-abdominal bowel gas. Massive pleural effusion, pneumo-or hemothorax. Severe tricuspid valve regurge with mean pulmonary artery pressure more than $50 \mathrm{mmHg}$ by transthoracic echocardiography, denoting cardiac right side dysfunction with subsequent systemic venous congestion. Neck and upper chest burns, previous neck radiotherapy or local site infection at site of CVP insertion.

\section{Monitoring:}

Standard monitoring was applied, including non-invasive arterial blood pressure, electrocardiography and pulse oximetry using the multichannel monitor.

\section{Measurements:}

1- Hemodynamic parameters: Heart Rate (HR) and Mean Arterial Pressure (MAP) were monitored before start of fluid therapy and after 1 , 4 and 8 hours.

2- Central Venous Pressure (CVP): A transducer used to measure the central venous pressure was fixed at the level of the patients phlebostatic axis, the level at which the fourth intercostal space meets the midaxillary line (normal value between 5 to $10 \mathrm{~cm} \mathrm{H}_{2} \mathrm{O}$ ), after zeroing, the transducer was left open to the central venous catheter. CVP waveform displayed on the monitor with the average central venous pressure measured in $\mathrm{cm} \mathrm{H} 2 \mathrm{O}$. This provided a means to measure the CVP continuously. This measurement was taken by the same intensive care physician and assistant nurse.

3- Ultrasound measurements: Maximum IVC diameter at end expiration (IVCdmax): A curvilinear probe of SonoSite turbo ultrasound machine was used. The internal Anterior Posterior (AP) diameter of the IVC just caudal to the confluence of the hepatic veins in the longitudinal plane was measured.

The IVC diameter variation ratio or IVC collapsibility index (IVC CI): It is the difference between the maximum (normal value between 1.7 to $2.5 \mathrm{~cm}$ ), and minimum IVC diameters (normal value between 1.0 to $1.5 \mathrm{~cm}$ ) divided by the maximum IVC diameter, expressed as ([IVCdmaxIVCdmin]/IVCdmax). Normal range of IVC-CI ranging between 0.2 to 0.5 values more than 0.5 suggests hypovolemia and values less than 0.2 suggest loss of IVC contractions as in hypervolemia or vasoplegia. After clinical assessment for signs of shock in the form of hypotension, (defined as mean arterial blood pressure less than $60 \mathrm{mmHg}$ in two consecutively reading). Tachycardia (more than $120 \mathrm{~b} /$ minuts), prolongation of capillary refill $>3$ second. We gave $500 \mathrm{~mL}$ of NacL $0.9 \%$ was administered in 15 minutes and clinical response was observed, measured using ultrasound then patients are divided into responder and non responder. The previous measurements were recorded in a spontaneously breathing patient at the following timings: Baseline measurement before start of fluid therapy, after 1, 4 and 8 hours of start of fluid resuscitation.

\section{Statistical analysis:}

Data were collected, revised, coded and entered to the Statistical Package for Social Science (IBM SPSS) version 20 and the following were done: 
Qualitative data were presented as number and percentages while quantitative data were presented as mean, standard deviations and ranges. The comparison between two independent groups with quantitative data and parametric distribution was done by using independent $t$-test. Pearson correlation coefficients were used to assess the correlation between two studied parameters in the same group. The confidence interval was set to $95 \%$ and the margin of error accepted was set to $5 \%$.

\section{Results}

The current study showed that 24 patients of 40 patient $(60 \%)$ responded to volume resuscitation. While 16 patients of 40 patients $(40 \%)$ didn't respond to volume resuscitation regimen, and their blood pressure improved only after introduction of vasopressor.

Descriptive statistical analysis of the study sample showed that the test group had a mean age of $51.16 \pm 5.61$ years. While gender distribution showed higher prevalence in females $25(62.5 \%)$ compared to males $15(37.5 \%)$. The test sample subjects have shown mean value of body mass index of $28.2 \pm 1.1 \mathrm{~kg} / \mathrm{m}^{2}$

Table (1): Demographic data distribution.

$\begin{array}{ll}\text { Sex: } & \\ \text { Male } & 15(37.5 \%) \\ \text { Female } & 25(62.5 \%) \\ \text { Age (years) } & 51.16 \pm 5.61 \\ \text { Weight }(\mathrm{kg}) & 70.14 \pm 9.01 \\ \text { Height }(\mathrm{cm}) & 168.23 \pm 7.55 \\ \text { BMI }\left(\mathrm{kg} / \mathrm{m}^{2}\right) & 28.2 \pm 1.1\end{array}$

Table (1) shows that there was no significant difference between both groups as regard demographic data.

Table (2): Comparison between responders and non-responders according to MAP.

\begin{tabular}{lcccc}
\hline $\begin{array}{l}\text { MAP } \\
(\mathrm{mmHg})\end{array}$ & \multicolumn{2}{c}{ Responder Non responder Independent } & \multicolumn{2}{c}{$p^{-}$} \\
& $(\mathrm{n}=24)$ & $(\mathrm{n}=16)$ & & \\
v-test & value \\
\hline Baseline & $53.68 \pm 0.47$ & $53.90 \pm 2.49$ & 0.424 & 0.674 \\
After 1hr & $58.62 \pm 3.85$ & $52.43 \pm 3.33$ & 5.249 & $<0.001$ \\
After 4hrs & $64.34 \pm 3.95$ & $49.43 \pm 3.04$ & 12.768 & $<0.001$ \\
After 8hrs & $66.34 \pm 4.10$ & $50.61 \pm 3.56$ & 12.510 & $<0.001$ \\
\hline
\end{tabular}

Values are presented as mean \pm SD. $p$-value $<0.01$ highly significant.

Table (2) shows that there was no significant difference between both groups at zero time (baseline). In the volume responder group, the MAP was significantly higher compared with the volume non responder group at time intervals 1,4 and 8 hours.
Table (3): Comparison between responders and non-responders according to heart rate.

\begin{tabular}{lcccc}
\hline $\begin{array}{l}\text { HR } \\
\text { (Beat/min })\end{array}$ & $\begin{array}{c}\text { Responder } \\
(\mathrm{n}=24)\end{array}$ & $\begin{array}{c}\text { Non responder Independent } \\
(\mathrm{n}=16)\end{array}$ & $\begin{array}{c}p^{-} \\
\text {-test }\end{array}$ & value \\
\hline Baseline & $128.00 \pm 6.28$ & $130.04 \pm 5.09$ & 1.082 & 0.285 \\
After 1hr & $119.56 \pm 6.82$ & $128.39 \pm 4.96$ & 4.446 & $<0.001$ \\
After 4hrs & $112.82 \pm 5.98$ & $130.52 \pm 4.45$ & 10.104 & $<0.001$ \\
After 8hrs & $104.14 \pm 4.89$ & $132.00 \pm 4.86$ & 17.695 & $<0.001$ \\
\hline
\end{tabular}

Values are presented as mean \pm SD

$p$-value $<0.01$ highly significant.

Table (3) shows that there was no significant difference between both groups at zero time (baseline). In the volume responder group, the HR was significantly lower compared with the volume non responder group at time intervals 1,4 and 8 hours.

Table (4): Comparison between responder and non responder according to central venous pressure.

\begin{tabular}{lcccc}
\hline $\begin{array}{l}\text { CVP } \\
(\mathrm{cm} \mathrm{H} \text { H2O })\end{array}$ & $\begin{array}{c}\text { Responder } \\
(\mathrm{n}=24)\end{array}$ & $\begin{array}{c}\text { Non responder } \\
(\mathrm{n}=16)\end{array}$ & $\begin{array}{c}\text { Independent } \\
t \text {-test }\end{array}$ & $\begin{array}{c}p^{-} \\
\text {value }\end{array}$ \\
\hline Baseline & $1.86 \pm 1.55$ & $1.785 \pm 0.60$ & 0.184 & 0.855 \\
After 1hr & $3.8 \pm 1.72$ & $1.8 \pm 1.10$ & 4.115 & $<0.001$ \\
After 4hrs & $6.1 \pm 1.85$ & $2.2 \pm 0.78$ & 7.948 & $<0.001$ \\
After 8hrs & $8.02 \pm 2.07$ & $2.1 \pm 1.55$ & 9.746 & $<0.001$ \\
\hline
\end{tabular}

Values are presented as mean \pm SD.

$p$-value $<0.01$ highly significant.

Table (4) shows that there was no significant difference between both groups at zero time (baseline). In the volume responder group, the CVP was significantly higher compared with the volume non responder group at time intervals 1,4 and 8 hours.

Table (5): Comparison between responder and non responder according to inferior vena cava collapsibility index.

\begin{tabular}{lcccc}
\hline CI & $\begin{array}{c}\text { Responder } \\
(\mathrm{n}=24)\end{array}$ & $\begin{array}{c}\text { Non responder } \\
(\mathrm{n}=16)\end{array}$ & $\begin{array}{c}\text { Independent } \\
t \text {-test }\end{array}$ & $\begin{array}{c}p^{-} \\
\text {value }\end{array}$ \\
\hline \hline Baseline & $0.75 \pm 0.03$ & $0.5 \pm 0.06$ & 17.471 & $<0.001$ \\
After 1hr & $0.71 \pm 0.03$ & $0.46 \pm 0.05$ & 19.793 & $<0.001$ \\
After 4hrs & $0.60 \pm 0.03$ & $0.49 \pm 0.05$ & 8.709 & $<0.001$ \\
After 8hrs & $0.61 \pm 0.05$ & $0.38 \pm 0.06$ & 13.156 & $<0.001$ \\
\hline
\end{tabular}

Values are presented as mean \pm SD. $p$-value $<0.01$ highly significant.

Table (6): Correlation between CVP ( $\mathrm{cmH} 2 \mathrm{O})$ and caval index over the study periods, using pearson correlation coefficient in volume responders.

\begin{tabular}{lcccc}
\hline \multirow{2}{*}{ Time } & $\begin{array}{c}\text { CVP (cmHO) } \\
\text { Mean } \pm \text { SD }\end{array}$ & $\begin{array}{c}\text { CI } \\
\text { Mean } \pm \mathrm{SD}\end{array}$ & \multicolumn{2}{c}{$\begin{array}{c}\text { CVP (cmH2O) } \\
\text { \& caval index })\end{array}$} \\
\cline { 4 - 6 } & & & $r$ & $p$-value \\
\hline Baseline & $1.9 \pm 1.55$ & $0.75 \pm 0.03$ & -0.94 & 0.000 \\
After 1hr & $3.8 \pm 1.72$ & $0.69 \pm 0.03$ & -0.96 & 0.000 \\
After 4hrs & $5.49 \pm 1.85$ & $0.70 \pm 0.03$ & -0.94 & 0.000 \\
After 8hrs & $8.90 \pm 2.07$ & $0.64 \pm 0.05$ & -0.98 & 0.000 \\
\hline
\end{tabular}

Values are presented as mean \pm SD. $p$-value $<0.01$ highly significant 
Table (7): Correlation between CVP ( $\mathrm{cmH} 2 \mathrm{O})$ and caval index over the study periods, using pearson correlation coefficient in volume non responders.

\begin{tabular}{lcccc}
\hline & \multirow{2}{*}{$\begin{array}{c}\text { CVP } \\
\text { Time }\end{array}$} & $\begin{array}{c}\text { CI } \\
\text { Mean } \pm \text { SD }\end{array}$ & Mean $\pm \mathrm{SD}$ & \multicolumn{2}{c}{\begin{tabular}{c} 
CVP $(\mathrm{cmH} 2 \mathrm{\&})$ \\
\cline { 4 - 5 } \cline { 4 - 5 }
\end{tabular}} & & \multicolumn{2}{c}{$r$} & \multicolumn{2}{c}{$p$-value } \\
\hline Baseline & $1.69 \pm 0.60$ & $0.49 \pm 0.06$ & 0.356 & 0.096 \\
After 1hr & $1.81 \pm 1.10$ & $0.50 \pm 0.05$ & 0.149 & 0.498 \\
After 4hrs & $2.2 \pm 0.78$ & $0.46 \pm 0.05$ & 0.177 & 0.420 \\
After 8hrs & $1.91 \pm 1.55$ & $0.41 \pm 0.06$ & -0.095 & 0.666 \\
\hline Values are presen
\end{tabular}

Values are presented as mean \pm SD.

Table (5) shows that there was highly significant difference between both groups at different time points.

Table (6) shows that measurements of CVP and IVC-CI throughout the study in volume responder patients were found to be strongly correlated that is highly significant.

Table (7) shows that measurements of CVP and IVC-CI throughout the study in volume non responder patients were found to be not correlated.

\section{Discussion}

This study was done at Al-Zahraa University Hospitals, included 40 shocked patients admitted in the Intensive Care Unit and revealed two types of response to fluid resuscitation. Most patients (26 patients of 40) showed improvement with volume resuscitation as regard elevated MAP decreased HR, elevate central venous pressure, and decreased IVC-CI, these patients are considered volume responders.

However, some patients (14 patients of 40) showed no response or even deterioration with volume resuscitation as regard low MAP, high $\mathrm{HR}$, low central venous pressure and low fixed IVCC-CI despite maximal possible volume of fluid resuscitation necessitating use of vasopressor agents, these patients are considered volume non responders.

Among volume responder patients, there was a solid negative correlation between the central venous pressure and the IVC-CI in the form of caval index value decline with central venous pressure increase during patient resuscitation with subsequent hemodynamic improvement, denoting that measurement of the IVC-CI is a good non invasive indicator of fluid responsiveness in shocked patients.

While among volume non responder patients, there was a low fixed caval index value with low central venous pressure during patient resuscitation with no subsequent hemodynamic improvement, denoting that measurement of the IVC-CI is a good non invasive indicator of vasopressor agent start in shocked patients.

This study showed a statistically significant lower heart rate in volume responder patients compared to non-responders, in response to resuscitation. So, HR responsiveness to bolus resuscitation is considered as a good negative test to decide volume responsiveness. However, decrease in heart rate wasn't observed even in some patients in the volume responders. This might be explained by the fact that the causes of tachycardia are numerous and varied in our patients selection e.g. sepsis and hyperdynamic circulation.

This study showed a statistically significant increase of CVP for responder group compared to non-responder group, the group of patients who responded to fluid resuscitation had higher CVP values in contrast to lower CVP values in non responder group.

This also can be correlated with low caval index in non responder group when compared to higher caval index in responder group.

This study was in disagree with the study done by de Valley and his colleagues [5] in carried on 45 shocked patients, the IVC-CI was determined immediately and after $500 \mathrm{ml} \mathrm{NaCl} 0.9 \%$ was administered in 15 minutes. The clinical response was observed. An adequate response was defined as an increased in systolic blood pressure of at least $10 \mathrm{mmHg}$. Based on this definition patients were divided into responders and non responders. A low IVC-CI $(<0.37)$ in patients with signs of shock reliable predicted the absence of an adequate response to fluid therapy (negative predictive value $0.92)$. The positive predictive value of a high IVCCI was much lower (0.48) despite the fact that responders had a significantly higher pre-infusion IVC-CI than non-responders $(0.49$ vs. $0.32, p$ $0.014)$. An explanation for the absence of a blood pressure response in the group of patients with a higher IVC-CI than normal range might be that these patients represent a group requiring more volume therapy than $500 \mathrm{ml}$.

This study was in agreement with Yanagawa and his colleagues [6] in who measured IVC diameters in 35 trauma patients, with 10 of them in shock and 25 in a stable hemodynamic state, in emergency department. In their study, the IVC diameter at the end of expiration was measured in trauma patients with hemorrhagic shock at baseline 
and again after what was believed to be adequate fluid resuscitation (defined by the improvement of systolic blood pressure to a level greater than $90 \mathrm{mmHg}$ ). Individuals who were able to maintain a stable blood pressure after fluid resuscitation had a significant diameter increase in end-expiratory IVC, whereas those who remained hemodynamically unstable did not have a change in IVC diameter with resuscitation. The authors concluded that changes in IVC diameter in response to fluid resuscitation is a better indicator of adequate fluid resuscitation than vital signs.

The current study shows a significant negative correlation between CVP and IVC-CI over the periods of one, four and eight hours after baseline measurement in the volume responder group.

A prospective double-blind observational study by Worapratya and his Coleagues [7] in was conducted in the emergency room of a tertiary care center on shocked patients. The IVC-CI was calculated. The correlation of CVP and the IVC-CI were calculated by Pearson's coefficient among the 30 patients.

This study concluded that the IVC-CI measured by bedside ultrasound in the emergency room had a good correlation with CVP, a result that resonates with our study results.

In addition, Sridhar et al., [8] and Naghipour and Faridaalaee [9] reported that IVC ultrasonography index revealed a significant relation with CVP, this index is reliable in evaluating the intravascular volume.

A significant relation has been observed between IVC and CVP in different studies. For example to these studies was Ciozda et al., [10] who used a systemic method for evaluating the results of 21 last studied and found a considerable relation between IVC diameter and collapsibility when compared to CVP measurement. It was concluded that measuring the IVC collapsibility can be considered as reliable method for evaluating the intravascular volume as a substitute for measuring CVP.

Also the current study was in agreement with another study was carried in Al-Azhar University by Shalaby and his colleagues [11] in to evaluate the correlation between Central Venous Pressure (CVP) measurement and ultrasound measurements of the Inferior Vena Cava diameter, and Collapsibility Index (IVC-CI), aiming to evaluate the ultrasound as a noninvasive tool in assessment of intravascular volume status and fluid responsiveness in critically ill intensive care unit patients. 50 patients aged 30-60 years were involved in this single blinded correlational study. A significant negative correlation between CVP and IVC CI $(r=-0.788, p<0.001)$ showed that Inferior Vena Cava Collapsibility Index (IVC CI) had the most favorable performance in predicting CVP $<10 \mathrm{~cm}$ $\mathrm{H} 2 \mathrm{O}$.

This study was in agreement with Jassin et al., [12] who studied IJV collapsibility index vs IVC collapsibility index by paint of core ultrasound for estimation of CVP and comparative study with direct estimation of CVP who showed there was significant negative between IVC-CI and CVP and conducted that the IJV collapsibility index and IVC-CI can be used as a first-line approached for the bedside non invasive assessment of CVP/fluid status in critically patients.

These results were in agreement with Kumar Rao and his colleagues [1] who studied the correlation of ultrasonographic measurement of inferior vena cava collapsibility index with central venous pressure in diagnosis and management of neonatal shock showed there was a strong negative correlation, which was statistically significant, between CVP and IVC-CI.

\section{Conclusions:}

Inferior vena cava collapsibility index assessment is relatively safe option and sensitive at least when compared to measuring CVP.

\section{References}

1- KUMAR RAO Y., ARORA S., MIDHA T. and RAO N.: Correlation of Ultrasonographic Measurement of Inferior Vena Cava Collapsibility Index with Central Venous Pressure in Diagnosis and Management of Neonatal Shock. Iranian Journal of Neonatology IJN, 11 (3): 86-91, 2020.

2- GINES P., FERNANDEZ J., DURAND F. and SALIBA F.: Management of critically-ill cirrhotic patients. J. Hepatol., 56 (1): S13-24, 2012.

3- KITAKULE M.M. and MAYO P.: Use of ultrasound to assess fluid responsiveness in the Intensive Care Unit. Open Crit. Care Med. J., 3: 33-7, 2010.

4- BABAIE S., BEHZAD A., MOHAMMADPOUR M. andREISI M.A.: Comparison between the Bedside Sonographic Measurements of the Inferior Vena Cava Indices and the Central Venous Pressure While Assessing the Decreased Intravascular Volume in Children. Adv. Biomed. Res., 7: 97, 2018.

4- ILYAS A., ISHTIAQ W., ASSAD S., GHAZANFAR H., MANSOOR S., HARIS M., QADEER A. and AKHTAR A.: Correlation of IVC diameter and collapsibility index with central venous pressure in the assessment of intravascular volume in critically ill patients. Cureus, 9 (2), 2017. 
5- De VAlLEY S., OLG T.J., HOLMAN M., et al.: The caval index: An adequate non-invasive ultrasound parameter to predict fluid responsiveness in the Emergency Department? BMC Anesthesiology, 14: 114, 2014.

6- YANAGAWA Y., SAKAMOTO T. and OKADA Y.: Hypovolemic shock evaluated by sonographic measurement of the inferior vena cava during resuscitation in trauma patients. J. Trauma, 63 (6): 1245-8, 2007.

7- WORAPRATYA P., ANUPAT S., SUWANNANON R. and WUTHISUTHIMETHAWEE P.: Correlation of caval index, inferior vena cava diameter and central venous pressure in shock patients in the emergency room. Dovepress; 7: 512-6, 2014.

8- SRIDHAR H., MANGALORE P., CHANDRASEKARAN V.P., MANIKAM R.: Caval Aorta index and central venous pressure correlation in assessing fluid status! "Ultrasound Bridging the Gap". ISRN Emergency Medicine, Vol. No. 5,2012 .

9- NAGHIPOUR B. and FARIDAALAEE G.: Correlation between central venous pressure and inferior vena cava sonographic diameter; determining the best anatomic location. Emergency, 4 (2): 83, 2016.

10- CIOZDA W., KEDAN I., KEHL D.W., ZIMMER R., KHANDWALLA R. and KIMCHI A.: The efficacy of sonographic measurement of inferior vena cava diameter as an estimate of central venous pressure. Cardiovascular Ultrasound, 14 (1): 33, 2016.

11- SHALABY M., ROSHDY H.M., ELMAHDY W.M. and EL MEZAYEN A.E.F.: Correlation between central venous pressure and the diameter of inferior vena cava by using ultrasonography for the assessment of the fluid status in intensive care unit patients. The Egyptian Journal of Hospital Medicine, 72 (10): 5375-84, 2018.

12- JASSIM H.M., NAUSHAD V.A., KHATIB M.Y., CHANDRA P., ABUHMAIRA M.M., KOYA S.H. and ELLITTHY M.S.: IJV collapsibility index vs IVC collapsibility index by point of care ultrasound for estimation of CVP: A comparative study with direct estimation of CVP. Open Access Emergency Medicine: OAEM, 11: 65, 2019.

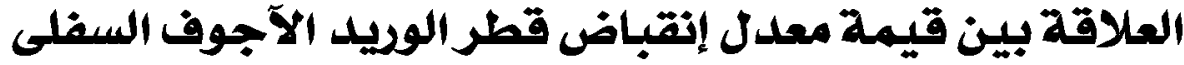

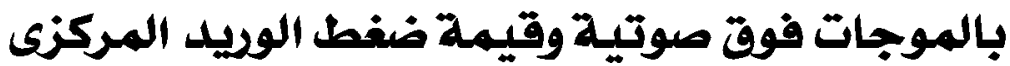

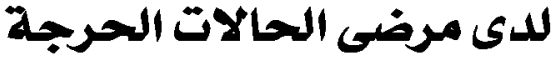

المقدمة: يعتبر زيادة آو نقص حجم السوائل المتواجدة بالجسم من الآسباب التى تزيد معدل الوفيات ولهذا فإن تقييم حجم السوائل

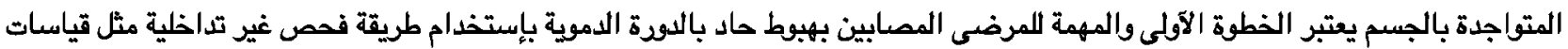

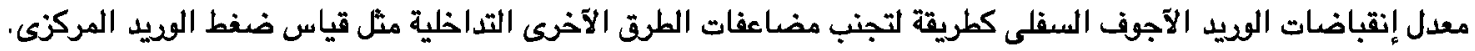

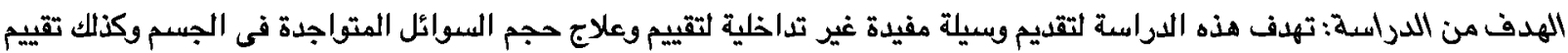
العلاقة بين قيمة معدل إنقباضات الويد الآجوف السفلى بإستخدام الموجات فوق الصوتية وبين ضغط الوفيد المركنى.

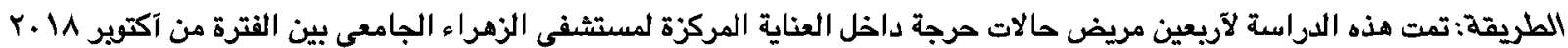

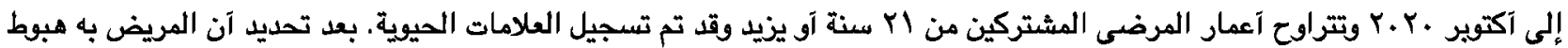

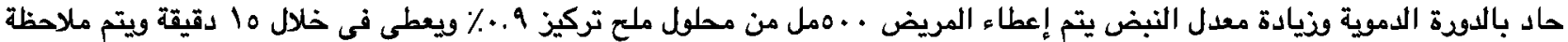

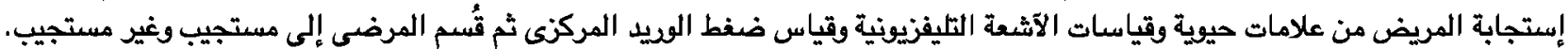

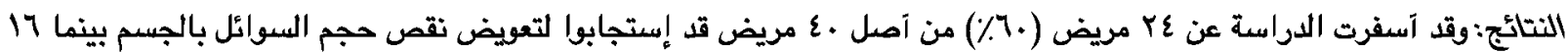

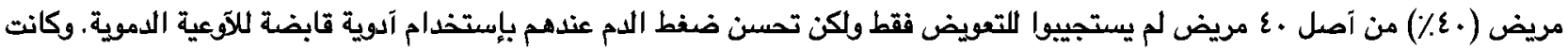

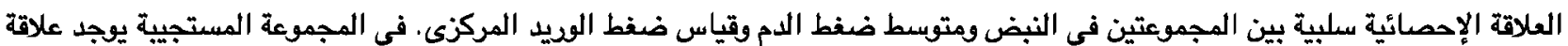

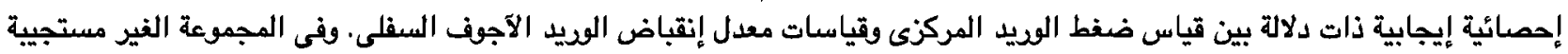

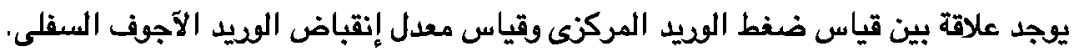

الإستتاج: يعتبر إستخدام الموجات فوق الصوتية على الوريد الآجوف السفلى طريقة آمنة ودقيقة بالمقارنة بقياس ضغط الوريد المركزى. 